\section{IJßER}

ISSN: 2149-5939
International Journal of Social Sciences and Education Research

Online, http://dergipark.gov.tr/ijsser

Volume: 3(1), 2017

\title{
Yeme bozukluklarında kişilik özellikleri
}

\author{
Personality traits in eating disorders
}

\author{
Ece Varlık Özsoy ${ }^{1}$
}

\begin{abstract}
Received Date: 01 / 09 / 2016
Accepted Date: 24 / 12 / 2016

$\ddot{O} z$

Yeme bozuklukları özellikle son yıllarda üzerinde yoğun bir şekilde çalışılan psikopatolojiler içerisinde yer almaktadır. Yeme bozukluklarının oluşumunda birçok biyolojik, psikolojik, sosyo-kültürel değişkenlerin etkili olduğu bilinmektedir. Yapılan araştırmalara bakıldığında yeme tutumu ve bozukluğu açısından ortak olarak beliren bazı kişilik yapısı veya özelliklerinden söz etmek mümkündür. Bu amaçla yeme bozukluklarıyla iliş̧ili çeşitli kişilik özelliklerinin tanımlanmasının, bozukluğun tedavisi ve önlenmesinde önemli bir yere sahip olabileceği düşünülmektedir. Yapılan araştırmalar sonucunda özellikle, mükemmeliyetçilik, öfke, düşük benlik saygısı, duyguları ifadede güçlük, aleksitimi (alextimia) gibi bir takım kişilik özelliklerinin yeme patolojisiyle ilişkili olduğu gözlenmiştir. Kişilik özelliklerinin oluşumunda, aile dinamikleri ve aile içi etkileşimin etkisi ise oldukça büyüktür. Bu nedenle bu makale, yeme bozukluklart ve kişilik özelliklerinin incelendiği araştırmalardan oluşan bir derleme niteliğindedir.
\end{abstract}

Anahtar Sözcükler: Yeme bozuklukları, kişilik özellikleri, aile dinamikleri

\begin{abstract}
Eating disorders are mainly located in the psychopathology studied intensively in recent years. Biological, psychological, socio-cultural variables are known to be effective for eating disorders. Considering the studies in this field, some personality traits or characteristics are common in eating attitudes and disorders. For this purpose, identification of the various personality traits that linked to eating disorders, are thought to have an important role in understanding, treatment and prevention in these disorders. The results of researches are showen that a number of personality traits such as perfectionism, anger, low self-esteem, difficulty in expressing emotions, alexithymia are observed to be associated with eating pathology. The effect of family dynamics and family interactions in development of personality traits are quite large. Therefore, this article is a rewiev, consisting of studies on eating disorders and personality traits.
\end{abstract}

Keywords: Eating disorders, personality traits, family dynamics

\section{Giriş}

Yiyecek ve yemeye yönelik olan ilgi özellikle son y1llarda oldukça artmıştır. Bu yoğun ilgi dikkate alındığında, insan davranışının bu yönünün, bir bozuklukla bağlantısının olması kaçınılmazdır. Klinik tanımlamalar oldukça geriye gitmekle birlikte, bu bozukluklar, DSM'de ilk kez 1980 yılında, çocukluk ya da ergenlik döneminde başlayan bozukluklarının, alt kategorisi olarak yer almıştır. Geçtiğimiz yirmi yıl süresince, klinisyenlerin ve araştırmacıların artan ilgisinden dolayı, DSM IV'ün basımı ile birlikte, yeme bozuklukları, anoreksiya nevroza ve bulimia nevroza olmak üzere ayrı bir kategori haline gelmiştir (APA, 2000). Son olarak DSM V'de beslenme ve yeme bozuklukları başlığı altında pika, geri çıkarma (geviş getirme) bozukluğu, kaçıngan kısıtlı yiyecek alım bozukluğu, anoreksiya nervoza, bulimiya nervoza, tıkanırcasına yeme bozukluğu,

\footnotetext{
${ }^{1}$ Öğr. Gör., Psk. Dr. (Klinik) Akdeniz Üniversitesi, Eğitim Fakültesi, Antalya, Türkiye,
} ecevarlik@akdeniz.edu.tr 
Varlık Özsoy, E. (2017). Yeme bozukluklarında kişilik özellikleri. International Journal of Social Sciences and Education Research, 3(1), 255-266.

tanımlanmış diğer bir yeme bozukluğu ile tanımlanmamış beslenme ve yeme bozukluğu ele alınmıştır (APA, 2013). Genel olarak, kadınlar üzerinde, erkeklere göre 'ince olma' ile ilgili daha fazla baskı bulunduğu söylenebilir. Bununla tutarlı olarak, kadınlardaki yeme bozukluğu oranlarının erkeklerden daha yüksek olduğu görülmektedir. Ancak son yıllarda, erkeklerin dış görünümlerinin daha zayıf ve kaslı bir yapıda olmasına ilişkin artan vurgu da dikkati çekmektedir (NolenHoeksema, 2004).

Yeme bozukluğu olan kişiler, yemek yeme ve kilo alımıyla ilgili yoğun endişe yaşarlar. $\mathrm{Bu}$ endişelerine bağlı olarak, yemeyle ilgili çeşitli davranışlar ortaya çıkmaktadır. Araştırmalar, yeme bozukluğunun üç belirli tipi üzerinde yoğunlaşmaktadır: Anoreksiya nevroza, bulimia nervoza ve tıkanırcasına yeme bozukluğu (Nolen-Hoeksema, 2004).

Anoreksiya nevroza (AN), kişinin yaşına ve boyuna uygun olarak normal ve sağlıklı kabul edilen vücut ağırlığını sürdürmeyi reddetmesine dayanan bir bozukluktur. Anoreksiklerin, çarpıtılmış beden imgeleri ile kilo almaya karşı aşırı korkuları bulunur. Bu hastalarda mensturasyon dönemlerinde düzensizlikler olduğu ya da bu dönemlerin kaybolduğu görülebilmektedir. Anoreksikler, çoğunlukla kendilerinin şişman olduğunu düşünürler, kilo verme ihtiyacı içindedirler. Anoreksiklerin kendileriyle ilgili değerlendirmeleri, vücut ağırlıklarına ve yemeleri üzerindeki kontrollerine dayanmaktadır. Yemelerini tamamen kontrol ettikleri ve kilo verdikleri zaman, kendilerinin iyi ve değerli olduğuna inanırlar. (Nolen-Hoeksema, 2004; Sayıl, 2000). Anoreksiya nervosanın yaygınlığ $\% 1$ civarındadır ve bu kişilerin \%90-95'i kadındır. Bu bozukluk, ergenlik döneminde yaklaşık 15-19 yaşları arasında başlamaktadır. Bozukluğun gidişatı kişiden kişiye değişmektedir. Anoreksiya nervosa, fizyolojik olarak tehlikeli bir bozukluktur. Anoreksikler arasındaki ölüm oranları \%5-8 civarındadır (Nolen-Hoeksema, 2004; Sayıl, 2000).

Bulimia nervozanın (BN) temel özelliği ise, kontrol edilemeyen yeme ya da tıkanırcasına yeme ve bunu izleyen kilo almayı engelleyici davranışlardır. Bulimik hastalarda, kilo almayı engellemek üzere, kendi kendini kusturma, laksatifler vb. kullanma, diyet yapma ve aşırı egzersiz yapma gibi davranışlar görülmektedir (Sayıl, 2000). Anoreksiklerde görüldüğü gibi, bulimiklerde de kişilerini kendilerine ilişkin değerlendirmeleri, vücut biçimleri ve ağırlıklarından etkilenmektedir. Bulimikler kendi beden biçimlerinden ve ağırlıklarından memnun olmayıp kilo vermeyle ilgili uğraş içindedirler (Nolen-Hoeksema, 2004; Sayıl, 2000). Bulimianın başlangıcı genellikle 12-29 yaşları arasındadır. Bulimia nervozaya sahip pek çok insanın normal kiloda ya da bir derece kilolu olduğu görülmektedir. BN kronik olmaya eğilimlidir (Nolen-Hoeksema, 2004).

Tıkanırcasına yeme bozukluğu, pek çok açıdan bulimia nervozaya benzemektedir. İki bozukluk, tıkanırcasına yeme bozukluğunda düzenli olarak dışa atım davranışlarının, diyet ya da aşırı egzersizlerin görülmemesi açısından ayrılmaktadır. Bir başka deyişle tıkanırcasına yeme bozukluğunun kilo almayı önleyici davranışlar olmadan yalnızca tıkanırcasına yeme davranışıyla karakterize olduğu söylenebilir. T1kanırcasına yeme bozukluğu olan bireyler oldukça kiloludurlar. Vücutlarını beğenmezler, aşırı yemelerinden utanırlar. Tipik olarak sık sık diyet yaptıklarına, kilo kontrol programlarına katıldıklarına ve ailelerinde obezitenin varlığına ilişkin öyküye sahiptirler (Nolen-Hoeksema, 2004; Davison ve Neale, 2004). Genel popülasyonun \%2'si bu bozukluğa sahiptir, kadınlarda erkeklere göre daha yaygın görülmektedir. Bu bozukluğa sahip kişilerde yüksek oranlarda depresyon, anksiyete, alkol kötüye kullanımı ve kişilik bozuklukları görülebilmektedir (Nolen-Hoeksema, 2004). 
Varlık Özsoy, E. (2017). Personality traits in eating disorders. International Journal of Social Sciences and Education Research, 3(1), 255-266.

\section{Yeme bozukluklarının etiyolojisine kısa bir bakış}

Yeme Bozukluklarının ortaya çıkışını etkileyen pek çok sosyokültürel, psikolojik ve biyolojik faktör bulunmaktadır. Zayıf ve çekici olmayla ilgili sosyal baskılar, güzellik standartları, sosyoekonomik düzey ve etnik köken, yemeyle ilgili uyumsal olmayan bilişler, acı veren duygularla başa çıkmada yiyeceklerin kullanılması, çeşitli aile dinamikleri ya da yapıları (müdahil olan aileler, etkileşimde karşılıklı bağımlılık ve gerginlik olan, mükemmeliyetçi, aşırı talepkar aileler), cinsel istismar, travmalar ve genetik yatkınlığın yeme bozukluklarının sebepleri arasında sayılmaktadır (Nolen-Hoeksema, 2004; Davison ve Neale, 2004). Bu bozukluğa sahip olan bireylerde genel olarak duygusal açıdan açlık olduğu görülmektedir. Bununla birlikte diğerlerinden onay alma ihtiyacı, düşük benlik saygısı, sık sık ortaya çıkan depresif duygular ve kaygı yeme bozukluklarında belirgin olarak görülen özelliklerdir (Nolen-Hoeksema, 2004).

\section{Yeme bozuklukları ve kişilik özellikleri arasındaki ilişkiler}

Bazı araştırmacılar, yeme bozukluğunun başlangıcından önceki dönemlerde, kişilik özelliklerine ilişkin geriye dönük veriler toplamışlardır. Bir araştırmada, kişilik özellikleri anoreksik vakalarda mükemmeliyetçi, utangaç, uysal olma; bulimik vakalarda ise histriyonik durumlar, duygulanımda dalgalanma ve sosyal açıdan dost canlısı bir mizaç sergilemek biçiminde gözlenmiştir (Fassino ve ark., 2004). Birçok araştırma da vakaların yeme bozukluğu tanısını almalarından sonra MMPI gibi uzun süredir kullanılan kişilik envanterlerinden yararlanarak kişilik özelliklerini değerlendirmeyi amaçlamıştır. Beş faktör modeli ve yeme bozuklukları arasındaki ilişkileri inceleyen çalışmalar yeme bozukluğu semptomlarının 5 faktör modelinde yer alan yüksek düzeyde nörotisizm ve deneyime açıklık, düşük düzeyde öz disiplin ve uyumluluk boyutlarıyla ilişkili olduğunu göstermiştir (Cassin ve Ranson, 2005).

Anoreksiklerin ve bulimiklerin kişilik özellikleri ve aileleriyle ilgili yapılan çalı̧̧malarda, aile ve kişilik özelliklerinin anoreksiyaya ya da bulimiyaya ne dereceye kadar sebep olduğu tam olarak bilinmemektedir, ancak ilişkinin yüksek olduğu görülmektedir (Nolen-Hoeksema, 2004). Bu konuda alanyazında geniş kapsamlı araştırmalar bulunmaktadır.

\subsection{Mükemmeliyetçilik}

Yıllardır, mükemmeliyetçilik ve psikolojik sorunlar arasında ilişki olduğu saptanmasına karşın, özellikle son zamanlarda, psikopatoloji ve mükemmeliyetçilik arasındaki ilişkiyi araştıran çalışmalar çoğalmıştır (Shafran, R. ve Mansell, W., 2001). Mükemmeliyetçilik; depresyon, intihar, yeme bozuklukları, sosyal anksiyete, obsesif kompulsif bozukluk, obsesif- kompulsif kişilik bozukluğu ve somatik bozukluklarda araştırılmış (Shafran, R. ve Mansell, W., 2001); mükemmeliyetçiliğin birçok bozuklukta olduğu gibi yeme bozukluklarında da rol oynadığı gözlenmiştir. Mükemmeliyetçiliği ilk tanımlayan Hollender, mükemmeliyetçilik için "kişinin kendisinin ya da diğerlerinin talep ve isteklerinin durumun ya da olayın gerektirdiğinden daha yüksek kalitede performans göstermek” tanımını kullanmıştır. Daha sonraları Burns bu konuda yaptığı birçok çalışmadan sonra, mükemmeliyetçiliği; beklentileri, olayın yorumlanması, kişinin kendisi ve diğerleri ile olan gelişim sürecini kapsayan "bilişlerin ağ örüntüsü/biliş ağı" (network of cognitions) olarak tanımlamıştır. Mükemmeliyetçi özelliğe sahip olanlar, genelde, gerçekçi olmayan yüksek standartlara sahip ve onlara sıkı bir şekilde bağlı, kendilerini de bu standartlara erişebildiklerinde değerli bulan kişiler olarak tanınırlar. Forst ve arkadaşları ise mükemmeliyetçiliği, "performans için çok yüksek standartların yaratılması ve buna kendilik gelişiminde aşırı derecede eleştirmenin 
Varlık Özsoy, E. (2017). Yeme bozukluklarında kişilik özellikleri. International Journal of Social Sciences and Education Research, 3(1), 255-266.

eşlik etmesi” olarak tanımlamışlardır. Bu yüksek standartlar ise yetersizlik korkusunu da beraberinde getirmektedir (Akt: Shafran ve Mansell, 2001). Kişi bu yüksek standartları karşılamak için çeşitli davranış örüntüleri sergileyebilir. Örneğin, dikkatlice kontrol etme, içini rahatlatmaya çalışmak, diğerlerinin yanlışlarını düzeltmeye çalışma, karar vermeden önce aşırı bir biçimde düşünme gibi. Alternatif olarak, fonksiyonel olmayan mükemmeliyetçi özelliğe sahip kişiler, genellikle, kişinin yüksek standartlarla karşı karşıya kalmayı gerektirecek durumlardan sakınırlar. Örneğin, bir işi ertelemek ya da yüksek standartlarla karşılaşmak hoş olmadığında işi ya da durumu erkenden sona erdirmek, hiç başlamamak gibi. Bununla birlikte, mükemmeliyetçiliğin "normal" olduğu, bazı zamanlarda tatmin edici, bazen olumlu bir uğraş olduğu ve de "olumlu-olumsuz" ya da "pasif-aktif" olarak da kategorilere ayrılması gerektiği de araştırılmıştır. Normal mükemmeliyetçiliğe sahip kişiler, nörotik mükemmeliyetçiliğe sahip kişilerle aynı şekilde yüksek standartlara sahip olmakla birlikte, farklı olarak, bu standartlar başarıldığında tatmin yaşarlar. Nörotik mükemmeliyetçiliğe sahip olan kişiler performanslarından asla memnun kalmazlar. Yeme bozukluklarında da psikopatolojiyle alakalı olan fonksiyonel olmayan, nörotik mükemmeliyetçilik üzerinde odaklanılmıştır.

Mükemmeliyetçiliğin oluşumunda alanyazında, talepkar ve mükemmeliyetçi anne ve babaların karşılıklı etkileşimi sonucunda ortaya çıktığı konusunda fikir birliği vardır. Farklı ebeveyn stillerinin de mükemmeliyetçilikle ilişkili olduğu bulunmuştur ve mükemmeliyetçi düşünme tarzı gelişimine katkıda bulunabilecek erken deneyimlerin dört tipi tanımlanmaktadır: Aşırı bir şekilde talepkar ve eleştirel ebeveynler; ebeveynlerin beklentilerinin, standartlarının aşırı bir şekilde yüksek ve eleştirilerinin dolaylı olması; ebeveynlerin onaylarının tutarsız, şartlı olması ya da hiç olmamasi; mükemmeliyetçi ebeveynlerin mükemmeliyetçi tutum ve davranışlarının çocuklarına model olması (Shafran ve Mansell, 2001). Yapılan bazı araştırmalarda, mükemmeliyetçiliğin, baba-kız arasında değil de özellikle anne-kız arasında yüksek korelasyon gösterdiğine ilişkin kanıtlar bulunmaktadır (Shafran ve Mansell, 2001). Yeme bozukluklarının özellikle ergenlik çağındaki kızlarda çok görülüyor olması ve de etiyolojisine bakıldığında özellikle psikodinamik kuramcılara göre, anne-kız arasındaki katı- eleştirel tutumun yeme patolojisin oluşumunda etkisinin olması mükemmeliyetçiliğin yeme bozukluklarında etkili olabileceğini düşündürtmektedir.

Yeme bozukluklarıyla mükemmeliyetçilik arasındaki ilişki biraz karışıktır ancak mükemmeliyetçilik anoreksiya ve bulimia nervozanın bilişsel kuramlarında da yer almıştır. (Fairburn, Shafran ve Cooper, 1999). Örneğin, mükemmeliyetçilik ile beden biçimi, kilo, katı ve aşırı diyet yapmakla aşırı uğraş arasındaki ilişki araştırılmış ve anlamlı bir ilişki bulunmuştur. Bir bakış açısına göre anoreksiya nervoza, mükemmeliyetçilikle ilişkilidir ve anoreksiya nervozanın oluşumu için gerekli bir özelliktir (Lilenfeld ve ark., 2006). Anoreksiya nervozası olan hastaların birçoğu "mükemmeliyetçi, itaatkar ve yalnız kızlar" olarak tanımlanırlar (Vitousek ve Manke, 1994). Yeme bozukluğunu değerlendiren bazı ölçek ya da anketler mükemmeliyetçiliği de değerlendiren alt ölçeklere sahiptirler. Örneğin, Yeme Bozukluğu Envanteri (Lampard, Byrne, Mclean ve Fursland, 2012). Hamli, Sunday, Strober, Kaplan, Woodside, Fichter, Treasure, Berrettini ve Kaye'nin (2000) yapmış olduğu bir çalışmada, anoreksik hastalar, klinik olmayan örnekleme oranla hem Çok Boyutlu Mükemmeliyetçilik Ölçeği'nden hem de Yeme Bozukluğu Envanterinin Mükemmeliyetçilik alt ölçeğinden daha yüksek puan almışlardır. Bulik, Tozzi, Anderson, Mazzeo, Aggen ve Sullivan'ın (2003) kadın hastalarla yaptıkları bir araştırmada, Çok Boyutlu Mükemmeliyetçilik Ölçeği sonuçlarının anoreksiya nervoza ve bulimia nervoza ile ilişkili olduğu bulunmuştur. $\mathrm{Bu}$ veriler göstermektedir ki, mükemmeliyetçilik özellikle anoreksiya nervozada güçlü ve ayırıcı bir özelliktir. 
Varlık Özsoy, E. (2017). Personality traits in eating disorders. International Journal of Social Sciences and

Education Research, 3(1), 255-266.

\section{2. Öfke}

Düşmanca tutum, sinirlilik, çabuk öfkelenme saldırganlığın bilinen dışavurumlarıdır. Kişilerdeki düşük tolerans düzeyi ve saldırganlık yeme bozukluğu olan kişilerde çok sık gözlenmektedir. Bu durum, aile ilişkileri ve örüntülerindeki ve de çocukluktaki yaşam olaylarının yorumlanmasındaki birtakım çarpıklıklar sonucu ortaya çıkmış olabileceğine dair kanıtlar vardır (Shugar ve Krueger 1995). Bazı araştırmacılar, bozuk yeme örüntüleri, kendi haklarını savunmadaki yetersizlik, yüksek düzeyde kendine yönelik saldırganlık ve öfkeyi ifade etmedeki güçlüklerin yeme bozukluklarıyla ilişkili olduğunu göstermiştir (Fassino, Daga, Piero, Leombruni, Rovera, 2001). Yeme bozukluklarındaki dürtüsel davranışların öfkeyi ifade etmekteki güçlüklerle ilişkili olabileceği düşünülmektedir. Ayrıca, yeme bozukluğu olan hastaların yediklerini çıkarma gibi bir takım garip davranışlarının da ifade edilemeyen öfkenin yüksek düzeyiyle ilişkili olabileceğine dair araştırmalar da bulunmaktadır (Fassino ve ark., 2001). Önceki çalışmalarda, bulimik hastalar, normal gruplara ve anoreksik hastalara oranla daha yüksek öfke düzeyi göstermişlerdir. Bu bulgular, bulimiklerin, öfkeye ve saldırganlığa yol açan düşük tolerans düzeyleri ve engellenmeleri, düşük dürtü kontrolünün anoreksiklere oranla daha çok olduğu, anoreksiklerin de kaçınma çatışmasının sonucu olarak yüksek düzey patolojik toleransa sahip olduklarını ve daha az kendilerine yönelik öfkeye ve saldırganlığa dönüştürme ve daha düşük düzey kendi haklarını savunma gösterme eğiliminde olduklarını desteklemektedir. Fassino ve arkadaşlarının yaptıkları (2001) çalışmada da bulimiklerin, anoreksiklere oranla daha yüksek öfke düzeyine sahip oldukları sonucuna ulaşılmıştır.

Björk, Clinton, Sohlberg, Hallström ve Norring' in (2003) yaptıkları bir çalışmada, yeme bozukluğu gösteren hastalar, klinik olmayan kontrol grubuna oranla anlamlı derecede yüksek negatif kişisel profil örüntüleri göstermiştir. Anoreksik hastalar, daha yüksek kendini kontrol etme, kendini suçlama ve kendine saldırma gösterirken, tıkanırcasına yeme bozukluğu olan hastalar en az olumsuz kendilik imajı ve bulimiklere oranla anlamlı derecede yüksek kendini onaylama ve atipik yeme bozukluğuna sahip hastalara oranla da anlamlı derecede daha düşük kendini kontrol etme davranışı göstermişlerdir (Björk ve ark, 2003).

Fassino ve arkadaşlarının (2003) yaptıkları başka bir araştırmada obez kişilerin, duygu durumu, yeme ile ilişkili psikopatolojiler, öfke düzeyleri ve öfkeyle başa çıkma tarzları incelenmiştir. Tıkanırcasına yeme bozukluğu gösteren obez hastalarda, normal kilodaki kontrol grubu ve tıkanırcasına yeme bozukluğunun eşlik etmediği obez hasta grubuna oranla daha fazla saldırganlık, eleştirel olma, aşırı öfke (öfke, dürtüsellikle ilişkili bulunmuş), depresif belirtiler ve yeme ile ilişkili psikopatoloji gözlenmiştir. Yüksek oranda depresyon belirtileri gösteren obez hastalarda öfkeyi bastırma eğilimi daha fazla bulunmuştur.

\subsection{Diğer kişilik özellikleri}

Vervaet, Heeringen ve Audenaert'in (2004) yaptıkları bir çalışmada anoreksiya nervoza kısıtlı tipi ile tıkanırcasına yeme bozukluğu ve bulumia nervoza hastalarının kişilik özellikleri arasındaki farklılıklar karşılaştırılmış ve bulimiklerin anoreksiklere oranla daha savurgan ve dürtüsel oldukları ve daha az kendini yönetme becerisi (self-directedness) gösterdikleri bulunmuştur.

Obezite, son yıllarda hızlı bir şekilde artmaya başlayan, karmaşık bir bozukluktur. DSM IV içerisinde yer almamaktadır. Ancak tıkınırcasına yeme bozukluğuna sıklıkla eşlik etmektedir (Fassin, Leombruni, Piero, Daga, Amianto, Rovera ve Rovera, 2002). Obez kişilerle yapılan çalışmalarda, bazı kişilik özellikleri meydana çıkmıştır: dürtüsellik, kendilik kontrolünün olmaması, 
Varlık Özsoy, E. (2017). Yeme bozukluklarında kişilik özellikleri. International Journal of Social Sciences and Education Research, 3(1), 255-266.

düşük benlik saygısı, mükemmeliyetçi tutumlar, ketlenmenin kalkması (disinhibition)ve düşük düzeyde sosyalleşme. (Fassino, Leombruni, Piero, Daga, Amianto, Rovera ve Rovera, 2002). Fassino ve arkadaşlarının (2002) tıkanırcasına yeme bozukluğu gösteren ve göstermeyen obez kadınlardaki mizaç ve karakteri inceledikleri bir çalışmada, tıkanırcasına yeme bozukluğunun eşlik ettiği obezlerde daha yüksek güvensizlik, sinirlilik ve pasiflik gözlenmesine rağmen genel olarak iki grup açısından benzer kişilik profillerine rastlanmıştır. Ayrıca tıkınırcasına yeme bozukluğu gösteren obez kadınlarda, bu bozukluğun olmadığı obez kadınlara oranla daha düşük kendini yönetme (self-directedness) düzeyi bulunmuştur (Fassino ve ark., 2002).

\section{Yeme bozuklukları, kişilik özellikleri ve cinsiyet farklılığı}

Yeme bozukluğu gösteren erkek hastaların kişilik özellikleriyle ilgili yapılan az sayıda çalışma bulunmaktadır. Bulimik erkek hastaların kadınlara oranla daha yüksek düzeyde mükemmeliyetçilik ve diğerlerine karşı güvensizlik gösterdikleri bulunmuştur (Woodside, Bulik, Thornton, Klump, Tozzi ve ark., 2004). Woodside, Bulik, Thornton, Klump, Tozzi ve arkadaşlarının yaptığı bir çalışmada (2004) da yeme bozukluğu gösteren erkeklerdeki kişilik özellikleri incelenmiştir. Sonuçlara göre, yeme bozukluğu gösteren erkekler, yeme bozukluğu gösteren kadınlara oranla daha az mükemmeliyetçilik, daha düşük zarardan sakınma, ödüle bağlılık ve işbirliği yapmama bulunmuştur. Bu sonuçlar, yeme bozukluklarında erkek- kadın kişilik özellikleri farklılıklarının incelendiği az sayıdaki çalışmalardaki sonuçlarla da tutarlıdır. Gözlenen bu farklılıklar yeme bozukluklarının kadın ve erkeklerdeki görülme sıklığı ve yaygınlığını açıklamakta yardımcı olabilir (Woodside, Bulik, Thornton, Klump, Tozzi ve ark., 2004).

\section{Yeme bozuklukları, kişilik özellikleri ve aile dinamikleri}

Hilde Bruch'ın yeme bozukluklarıyla ilgili önemli çalışmaları bulunmaktadır. Bruch'a göre, AN, "iyi kız” olarak bilinen, bir başka deyişle başarılı, görev ve sorumluk sahibi, itaatkar kızlarda görülmektedir. Her zaman mükemmel olmaya, ailelerini ve diğerlerini memnun etmeye çalışan bu kızlar, ailelerinin kontrolü altındadırlar. Aile, kızların istekleri ve başarıları üzerinde hakimiyet kurmaya eğilimliyken aynı zamanda duyguların özellikle de olumsuz duyguların ifade edilmesine izin vermezler (Bruch, 1973, 1978, 1988). Bruch'a göre (1973), bu aileler hayatları boyunca k1zlarına yönelik aile işlevlerini yerine getirmede etkisizdirler. Kızlarının rahatlık ve beslenme ihtiyaçlarından ziyade öncelikle kendi ihtiyaç ve programlarını yerine getirirler. Sonuç olarak bu kızlar, kendi duygu ve isteklerini kabul etmeyi ve belirlemeyi öğrenemezler; diğerlerinin ihtiyaç ve isteklerini öğrenip bu taleplere razı olurlar, benlikleri ve kimlikleriyle ilgili olarak bazı çatışmalar yaşarlar. Açlık gibi vücut duyumlarını da saptayamazlar. Bu durum da uzun zaman dilimlerinde açlıktan ölme durumuna gelmelerine yol açmaktadır. Bazı psikoanalitik teorisyenler, anoreksik kızların kendilerini aç bırakarak ergenlik dönemindeki olgunlaşmayı durdurduklarını ve böylece de cinsel olgunluk ve ilişkilerden kaçındıklarını öne sürmüştür (Nolen-Hoeksema, 2004).

Yeme bozukluğuna sahip bireyler yaşadıkları kaygı, depresyon, uyumsuz kişilik özellikleri ve stres verici hayat olaylarından söz etmişlerdir. Önceki çalışmalar, olumsuz vücut imgesi, düşük benlik değeri, obsesif-kompulsif özellikler, mükemmeliyetçilik, dışa vurum gibi belirtilerin yenme ve kilo problemlerinin gelişimiyle ilişkili olabileceğini öne göstermiş̦tir (Johnson, Cohen, Kotler, Kasen ve Brook, 2002). Bir hipoteze göre, mükemmeliyetçi olan gençler, yüksek olan standartlarıyla karşılaşmaları sonucundaki yetersizliklerinden dolayı ortaya çıkan depresyon ve kaygıyla baş etmek için tıkanırcasına yeme bozukluğu gösterebilirler (Johnson, Cohen, Kotler, Kasen ve Brook, 2002). Mükemmeliyetçilik ve obsesyonel olma, zayıf olmayı idealize eden 
Varlık Özsoy, E. (2017). Personality traits in eating disorders. International Journal of Social Sciences and Education Research, 3(1), 255-266.

gençler arasında, diet yapma ya da kilo verdirmeye yönelik diğer davranışların oluşmasına ve devam ettirilmesine katkı sağlıyor olabilir. Mükemmeliyetçi ya da obsesif, düşük beden imgesi, düşük benlik değerine sahip kızlar, ergenlik sonrasında, fiziksel ya da psikososyal stresli olaylar karşısında yeme bozukluğu gösterme açısından risk altında olabilirler.

Başka bir hipoteze göre, madde kötüye kullanımı ve diğer dışsallaştırıcı davranışlar (externalizing behaviors), yeme bozukluklarının oluşumu açısından bir risk faktörü olabilir, bunun nedeni, dürtü kontrolünün olmayışı ve duygulanımdaki değişkenlik, ödünleyici tıkanırcasına yeme davranışlarının oluşmasında etkili olması şeklinde açıklanabilmektedir. (Johnson, Cohen, Kotler, Kasen ve Brook, 2002). Johnson ve arkadaşlarının yaptıkları bir çalışmada (2002), ergenlik dönemi boyunca ve genç yetişkinlik döneminde kaygı, depresiflik, engellenme, kişilik bozuklukları ve madde kötüye kullanımı, yeme bozuklukları oluşumunda ve devam etmesinde risk faktörleri oldukları bulunmuştur.

Yeme bozukluğu olan kız çocuklarının ebeveynlerinde "Aleksitimi”" ve psikopatoloji ve kişilik değişkenleri incelenmiştir (Espina, 2003). "Aleksitimi”; öznel duyguların tanımlanması ve anlatılmasındaki güçlülük; duygular ve vücut duyumlarının duygusal uyarımları arasındaki ayrımdaki güçlük; hayal kurma eksikliği; dışsal odaklı bilişsel stil ile karakterize bir olgudur. Birçok araştırmac1, bu özelliklerin duyguların bilişsel işleme sürecindeki hasar nedeniyle oluşabileceğini söylemektedir. Aleksitimi; nörotisizm, depresyon, kaygı, psikotizm, içe dönüklük ile pozitif korelasyon, dışa dönüklük, toplum içerisinde olmaktan hoşnutluk duyma ile negatif korelasyon göstermektedir. Aleksitimi, birçok farklı patolojilerle ilişkili bulunmuştur: somatoform bozuklukları, alkolizm, madde bağımlılığı, travma sonrası stres, astım, depresyon, yeme bozuklukları gibi (Espina, 2003). Bruch, duyguları tanımlama ve ayırt etmedeki güçlüklerin (duygusal ifadeler ve iç organların duyumlarına verilen tepkiler ve onları tanımlama), yeme bozukluklarının temel noktasını oluşturduğunu ileri sürmektedir (Bruch, 1988). Espina'nın yaptı̆̆ı bir çalışmada (2003), yeme bozukluğu gösteren kızların annelerinde, yeme bozukluğu göstermeyen kızların annelerine göre daha yüksek oranda aleksitimi gösterdikleri bulunmuştur. Yeme bozukluğu gösteren kız çocuklarının ebeveynlerindeki aleksitimi, bir kişilik özelliği olabileceği gibi, strese verilen tepkiler nedeniyle de olabilir (Espina, 2003).

\section{Yeme bozuklukları ile kişilik bozuklukları arasındaki ilişkiler}

Kişilik değişkenleriyle yeme bozuklukları arasındaki ilişkiler bir yana; yeme bozuklukları ile kişilik bozuklukları arasındaki ilişkiler de incelenmiştir. Yeme bozuklukları ile komorbidite gösteren psikolojik bozukluklardan birisi de kişilik bozukluklarıdır. Yeme bozukluklarına uyumsuz bir takım kişilik özelliklerinin eşlik etmesi, kuşkusuz ki bu boyutlardaki patolojilerin ortaya çıkabileceğini akla getirmektedir. Alan yazında yeme bozuklukları ile kişilik bozuklukları arasındaki ilişkiyi inceleyen birçok araştırmaya rastlanmaktadır. Yapılan çalışmalarda, C kümesi kişilik bozukluklarının (kaygıl1, korkulu özelliklerin yoğun olduğu), anoreksik hastalarda \%0-26 arasında, B kümesi kişilik bozukluklarının (dramatik, duygusal özelliklerin yoğun olduğu) da bulimik hastalarda \%2-50 arasında görüldüğü rapor edilmiştir (Godt, 2002; Ilkjaer, Kortegaard, Hoerder, Joergensen, Kyvik, ve Gillberg, 2004; Fassino ve ark., 2001).

Davis, Claridge ve Cerullo'nun (1997), yapmış olduğu bir çalışmada, yeme patolojisi ve ile kişilik bozukluklarının ilişkisine bakıldığında, yeme patolojisi gösteren hastalarda özellikle borderline ve narsisizm özelliklerinin, klinik olmayan örnekleme göre açık bir şekilde daha fazla 
Varlık Özsoy, E. (2017). Yeme bozukluklarında kişilik özellikleri. International Journal of Social Sciences and Education Research, 3(1), 255-266.

olduğu bulunmuştur. Westen ve Harnden-Fischer'in (2001), yapmış oldukları bir çalışmada, k1sitlı anoreksiklerin tıkanırcasına yeme bozukluğu olan anoreksiklere ve bulumik hastalara oranla daha şizoid ve obsesif kompulsif kişilik bozukluğuna meyilli olduklarını göstermiş̧ir. Anoreksik ve bulumik belirtilerin ikisini birden gösteren hastalar, tek başına bulumia tanısı almış hastalara oranla daha fazla borderline kişilik bozukluğu belirtileri göstermişlerdir (Westen ve HarndenFischer, 2001). Milos, Spindler ve Buddeberg' in (2003) yapmış olduğu başka bir araştırmada da yeme bozukluğu gösteren hastaların \%52'si C kümesi kişilik bozuklukları, \%23'ü B kümesi kişilik bozuklukları göstermişlerdir.

Yapılan çalışmalarda bulimiklere en sık eşlik eden kişilik bozukluğunun borderline kişilik bozukluğu olduğu gözlenmiştir. Özellikle B kümesi kişilik bozuklukları bulimiklerde gözlenirken, anoreksiklerde ise $\mathrm{C}$ kümesi kişilik bozukluklarından obsesif-kompulsif kişilik bozukluğu daha çok gözlenmektedir (O'Brien ve Vincent, 2003, Ilkjaer, Kortegaard, Hoerder, Joergensen, Kyvik, Gillberg, 2004). Bulimik hastalara borderline kişilik bozukluğunun eşlik etmesi, iki bozuklukta da dürtüselliğin ön planda olmasıyla ilişkili olabilir. Benzer olarak anoreksiklerin obsesif kompulsif kişilik bozukluğuyla birlikte görülmesi, mükemmeliyetçilik, katı tutum ve detaylarla saplantılı bir şekilde uğraşmakla ilişkili olabilir (O'Brien ve Vincent, 2003). Alan yazındaki son tartışmalar, anoreksiya nervosanın obsesif kompulsif bozukluk ve obsesif kompulsif kişilik bozukluğuyla oldukça yüksek komorbidite göstermesi sebebiyle, bu üç bozukluğun birbiriyle karışması ya da bu üç bozukluğun birbirinin alt kategorileri içerisinde yer alıp almaması üzerine odaklanmıştır (Serpell, Livingstone, Neiderman, Lask, 2002).

Yapılan bir başka çalışmada, tıkanırcasına yeme bozukluğu hastalarının kaçıngan kişilik bozukluğuyla yüksek bir komorbidite gösterdiği bulunmuştur (Grilo, 2004). Başka bir çalışma ise tıkanırcasına yeme bozukluğuna sahip obez hastalarda ise borderline kişilik bozukluğunun yüksek bir komorbidite gösterdiği bulunmuştur (Sansone, Wiederman, Sansone, 2000).

\section{Tartışma ve sonuç}

Yeme bozuklukları, kişilik bozuklukları ile yüksek komorbidite göstermektedir. Kişilik bozukluklarının oluşumunda uyumsuz kişilik özelliklerinin rolü tartışmasız büyüktür. Yapılan çalışmalarda, yeme bozukluklarında da bir takım kişilik örüntülerinin etkili olduğu gözlenmiştir. Bu kişilik özellikleri büyük oranda kişilik bozukluklarının altında yatan kişilik örüntüleriyle benzeşmektedir. Yapılan birçok çalışmada, örneğin mükemmeliyetçiliğin, nörotik boyutun anoreksik hastalarda ve obsesif kompulsif kişilik bozukluğu olan hastalarda birlikte gözlendiği, bulimik hastalarda ise öfke, aşırı dürtüsellik gibi, borderline kişilik bozukluğu içerisinde de yer alan birtakım özelliklerin birlikte gözlendiği bilinmektedir. Bu durum, yeme bozukluğu gösteren hastaların ileride ya da eş zamanlı olarak kişilik bozuklukları da gösterebileceği üzerindeki olasılığın yüksek olduğunu göstermektedir. Yine aynı şekilde, kişilik bozukluğu gösteren hastaların yeme patolojisi de gösterebilme olasılıkları yüksektir.

Kuşkusuz ki kişiliğin oluşumunda aile ve yaşanılan çevrenin önemi büyüktür. Çoğunlukla model alarak öğrenme, aile içi etkileşim sonucu çocuğun verdiği tepkileri ve onun karakterini belirlemede önemli bir rol oynamaktadır. Yeme patolojisi gösteren kişilerin aile örüntülerine bakıldığına, uyumsuz, katı, sert, kontrol sağlamaya yönelik, aşırı talepkar, beklentileri yüksek ve mükemmeliyetçi tutum sergiledikleri görülmektedir. Bu nedenle yeme patolojisi gösteren çocuklar, ailelerindeki bu davranış örüntülerini öğrenmiş olabilirler. Ayrıca, ailedeki bu örüntülerle baş etmek için yeme bozukluğu geliştirdikleri de düşünülebilir. 
Varlık Özsoy, E. (2017). Personality traits in eating disorders. International Journal of Social Sciences and Education Research, 3(1), 255-266.

Sonuç olarak, aile içi etkileşime, ailenin özelliklerine, ebeveynlerin kişilik özelliklerine yeme patolojisini önleme programlarında yer verilmelidir. Yeme bozukluklarındaki kişilik özelliklerinin anlaşılması, yeme patolojisinin oluşumu ve oluştuktan sonraki tedavisi açısından yeni bilgiler sağlayabileceği ve bu patolojilerin daha iyi anlaşılıp, daha uygun ve başarılı tedavi tekniklerinin uygulanabileceği düşünülmektedir.

\section{Kaynakça}

Amerikan Psikiyatri Birliği (2000). Psikiyatride hastalıkların tanımlanması ve sinıflandırılması elkitabl, Yeniden gözden geçirilmiş dördüncü baskı (DSM IV-TR), Amerikan Psikiyatri Birliği, Washington DC, 2000'den Çeviren Köroğlu, E. Hekimler Yayın Birliği, Ankara, 2001.191-195

Amerikan Psikiyatri Birliği (2013). Psikiyatride hastalıkların tanımlanmast ve slnıflandırılması elkitabl, Beşinci baskı (DSM V), Amerikan Psikiyatri Birliği, Washington DC, 2013'den Çeviren Köroğlu, E. Hekimler Yayın Birliği, Ankara.

Björck, C., Clinton, D., Sohlberg, S., Hallström, T. Ve Norring, C. (2003). Interpersonal Profiles in Eating Disorders: Ratings of SASB Self-Image. Psychology and Psychotherapy: Theory, Research and Practice, 76, 337-349.

Bruch, H. (1973). Eating Disorders: Obesity, Anorexia Nervosa and the Person Within. Basic

Books: New York.

Bruch, H. (1978) The Golden Cage: The Enigma of Anorexia Nervosa. Cambridge, MA: Harvard University Press.

Bruch, H. (1988) Conversations with Anorexics. New York: Basic Books.

Bulik, C. M., Tozzi, F., Anderson, C., Mazzeo, S. E., Aggen, S., Sullivan, P. F. (2003). The Relation Between Eating Disorders and Components of Perfectionism. American Journal of Psychiatry, 160, 366-368.

Cassin, S. E., ve Ranson, K. M. (2005). Personality and eating disorders: A decade in review.

Clinical Psychology Review, 25, 895-916.

Davis, C., Claridge, G. ve Cerullo, D. (1997). Personality Factors and Weight Preoccupation: A Continuum Approach to the Association Between Eating Disorders and Personality Disorders. Journal Psychiatry Res., Vol.31, No.4, 467-480.

Davison G. C, Neale, J. M. (2004). Anormal Psikolojisi (7. Basım) (Çev.Ed. İhsan Dağ) içinde (213-234). Ankara: Türk Psikologlar Derneği. (Orijinal çalışma basım tarihi 1998).

Espina, A. (2003). Alexithymia in Parents of Daughters with Eating Disorders, Its Relationships with Psychopathological and Personality Variables. Journal of Psychosomatic Research,55, 553-560.

Fairburn, C. G., Shafran, R., ve Cooper, Z. (1999). A Cognitive- Behavioral Theory of Anorexia Nervosa. Behaviour Research and Therapy, 37, 1-13.

Fassino, S., Amianto, F., Gramaglia, C., Facchini, F., Abbate Daga, G. (2004). Temperament

and character in eating disorders: ten years of studies. Eat Weight Disord. Jun;9(2):81-90.

Fassino, S., Daga, G. A., Piero, A., Leombruni, P., Rovera, G. G. (2001). Anger and Personality in Eating Disorders. Journal of Psychosomatic Research, 51, 757-764.

Fassino, S., Leombruni, P., Piero, A., Daga, G. A., Rovera, G. G.(2003). Mood, Eating Attitudes, and Anger in Obese Women with and Without Binge Eating Disorder. Journal of Psychosomatic Research 54, 559566.

Fassino, S., Leombruni, P., Piero, A., Daga, G. A., Amianto, F., Rovera, G. ve Rovera, G. G.(2002). Temperament and Character in Obese Women With and Without Binge Eating Disorder. Comprehensive Psychiatry, Vol.43, No.6, 431-437. 
Varlık Özsoy, E. (2017). Yeme bozukluklarında kişilik özellikleri. International Journal of Social Sciences and Education Research, 3(1), 255-266.

Godt, K. (2002). Personality disorders and eating disorders: the prevalence of personality disorders in 176 female outpatients with eating disorders. European Eating Disorders Review, 10, 102-109.

Grilo, C.M. (2004). Factorial Structure and Diagnostic Efficiency of DSM-IV Criteria for Avoidant personality Disorder in Patiennst with Binge Eating Disorder. Behaviour Research and Therapy 42, 11491162.

Hamli, K.A., Sunday, S.R., Strober, M., Kaplan, A., Woodside, D.B., Fichter, M., Treasure, J., Berrettini, W. H., Kaye, W. H. (2000). Perfectionism in Anorexia Nervosa: Variation by Clinical Subtype, Obsessionality, and Pathological Eating Behavior. American Journal of Psychiatry, 157, 1799-1805.

IIkjaer, K., Kortegaard, L., Hoerder, K., Joergensen, J.,Kyvik, K. And Gillberg, C. (2004). Personality Disorders in a Total population Twin Cohort With Eating Disorders. Comprehensive Psychiatry, Vol.45, No.4, 261-267.

Johnson, J. G., Cohen, P., Kotler, L., Kasen, S.ve Brook, J.S. (2002). Psychiatric Disorders Associated with Risk for the Development of Eating Disorders During Adolescence and Early Adulthood.Journal of Consulting and Clinical Psychology, Vol 70, No.5, 1119-1128.

Lampard, A., Byrne, S., Mclean, N., \& Fursland, A. (2012). The Eating Disorder Inventory-2 Perfectionism scale:Factor structure and associations with dietary restraint and weight and shape concern in eating disorders. Eating behaviors, 13, 49-53.

Lilenfeld, L.R., Wonderlich, S., Riso, L.P., Crosby, R., and Mitchell, J. (2006). Eating disorders and personality: A methodological and empirical review. Clinical Psychology Review, 26, 299-320

Milos, G. F., Spindler, A. M. ve Buddeberg, C. (2003). Axes 1 and 2 Comorbidity and Treatment Experiences in Eating Disorder Subjects. Psychotherapy and Psychosomatics, 72, 276-285.

Nolen- Hoeksema, S. (2004). Abnormal Psychology. New York: The McGraw-Hill Companies.

O’ Brien, K.M.\& Vincent, N.K. (2003). Psychiatric comorbidity in Anorexia and Bulimia Nervosa: Nature, Prevalence, and Causal Relationships. Clinical Psychology Review, 23, 57-74.

Sansone, R.A., Wiederman, M.,W.ve Sansone, L.A. (2000). The Prevalence of Borderline Personality Disorder among Individuals with Obesity: A Critical Review of the Literature. Eating Behaviors, 1, 93104.

Sayıl, I. (Ed.). (2000). Ruh Sağlı̆̆l ve Hastalıkları (2. Baskı) içinde (355-369). Ankara: Öncü Basımevi.

Serpell, L., Livingstone, A., Neiderman, M.\& Lask, B. (2002). Anorexia Nervosa: Obsessive-Compulsive Disorder, Obsesive-Compulsive Personality Disorder, or Neither? Clinical Psychology Review, 22, 647-669.

Shafran, R. ve Mansell, W. (2001). Perfectionism and Psychopathology: A Review of Research and Treatment. Clinical Psychology Review, Vol.21, No.6, 879-906

Shugar, G. ve Krueger, S. (1995). Agressive Family Communication, Weight Gain, and Improved Eating Attidudes During Systematic Family Therapy for Anorexia Nervosa. International Journal of Eating Disorders, 17, 23-31.

Westen, D., Harnden-Fischer, J. (2001). Personality Profiles in Eating Disorders: Rethinking the Distinction Between Axis 1 and Axis 2. American Journal of Psychiatry, 158, 547-562.

Woodside, D.B. ve Diğerleri (2004). Personality in Men with Eating Disorders. Journal of Psychosomatic Research 57, 273-278.

Vervaet, M., Heeringen, C.V. ve Audenaert, K. (2004). Personality-Related Characteristics in Restricting Versus Binging and Purging Eating Disordered Patients. Comprehensive Psychiatry, Vol.45, No.1, 37 43.

Vitousek, K., ve Manke, F. (1994). Personality Variables and Disorders in anorexia Nervosa and Bulumia Nervosa, Journal of Abnormal Psychology, 103, 137-147. 
Varlık Özsoy, E. (2017). Personality traits in eating disorders. International Journal of Social Sciences and Education Research, 3(1), 255-266.

\section{Extended abstract in English}

People with eating disorders experience severe anxiety about eating and gaining weight, which leads to a number of strange eating behaviours. The research in this field has focused on three specific types of eating disorders: anorexia nervosa, bulimia nervosa, and binge eating disorder (Nolen-Hoeksema, 2004).

Anorexia nervosa (AN) is a disorder characterized by refusal to maintain a body weight considered healthy for a person's age and height. The core characteristics of bulimia nervosa (BN), on the other hand, include compulsive binge eating, which is followed by compensatory behavior to prevent weight gain, such as self-induced vomiting, using laxatives, dieting and excessive physical activity (Say1l, 2000). Binge eating disorder may resemble bulimia nervosa in several aspects, though it involves no regular purging, dieting or excessive physical exercise. People with binge eating disorder often tend to be overweight.

Some researchers have collected retrospective data on personality traits existent prior to the onset of eating disorder. One study observed perfectionism, shyness, and submissive behaviour in anorexic patients, while bulimic patients exhibited histrionic behavior patterns, affective fluctuations, and extroversion (Fassino et al., 2004). Research into the relationship between the fivefactor model and eating disorders has revealed that symptoms of eating disorders are associated with high levels of neuroticism and openness to experience and low levels of self-discipline and agreeableness (Cassin and Ranson, 2005).

Studies have found significant relationships between eating disorders and perfectionism. One view associates anorexia nervosa with perfectionism, considering it an essential characteristic of this disorder (Lilenfeld et al., 2006). Patients with anorexia nervosa were described as "perfectionist, obedient, and lonely girls" (Vitousek and Manke, 1994). A study by Bulik, Tozzi, Anderson, Mazzeo, Aggen and Sullivan (2003) found that the results of the Multidimensional Perfectionism Scale were associated with anorexia and bulimia. These data show that perfectionism is a powerful and distinctive feature in anorexia nervosa.

Impulsivity in eating disorders might be related to difficulties in expressing anger. Some studies suggest that strange behaviors like self-induced vomiting may be associated with high level of unexpressed anger (Fassino et al., 2001). The study by Fassino et al. (2001) found that bulimic patients had a higher level of anger than did anorexic patients.

Hilde Bruch conducted some influential research into eating disorders. According to Bruch, anorexia commonly occurs in "good girls", or successful, task-oriented, responsible, obedient girls who always try to be perfect and satisfy their parents and others. Such parents tend to control the daughter's desires and achievements, not allowing her to express emotions, particularly those negative ones (Bruch, 1973, 1978, 1988).

Some studies investigated "alexithymia", psychopathology, and personality variables in the parents of girls with eating disorders (Espina, 2003). Alexithymia is characterized by inability to identify and describe subjective emotions, difficulty in distinguishing between feelings and bodily sensations of emotional stimuli, lack of imagination, and externally oriented cognitive style. Espina (2003) found that mothers of girls with eating disorders showed higher levels of alexithymia than did mothers of healthy daughters. The alexithymia seen in the parents of girls with eating disorders could be a personality trait, but it may well be a reaction to stress (Espina, 2003). 
Varlık Özsoy, E. (2017). Yeme bozukluklarında kişilik özellikleri. International Journal of Social Sciences and Education Research, 3(1), 255-266.

The relevant literature contains a wealth of research into the relationship between eating disorders and personality disorders. Cluster $\mathrm{C}$ personality disorders (anxious, fearful cluster) have been reported to have an incidence rate of $0-26 \%$ in anorexic patients and Cluster B (dramatic, overly emotional cluster) an incidence rate of 2\%-50\% in bulimic patients (Godt, 2002; Ilkjaer, Kortegaard, Hoerder, Joergensen, Kyvik, and Gillberg, 2004, Fassino et al., 2001).

Several personality patterns are observed to play a role in eating disorders. Such personality traits greatly resemble the personality patterns underlying the personality disorders. Previous studies observed coexistence of perfectionism and neurotic dimension in anorexia and obsessivecompulsive disorder, noting that bulimic patients exhibited certain traits common in borderline personality disorder, such as anger and extreme impulsivity.

Besides, the family patterns of individuals showing eating pathologies have been found to include maladaptive, strict, harsh, over-controlling, over-demanding, aspirational, and perfectionist attitudes. Therefore, children with eating pathology may be acquiring such patterns of behavior in their families. We could also suggest that these children develop eating disorders to cope with such patterns.

In conclusion, strategies designed to tackle eating pathology should also focus on familial interactions, family characteristics, and parental personality traits. A better understanding of personality traits in eating disorders may yield valuable insight into the development of eating pathology, which might facilitate the diagnosis and treatment of such pathologies in future. 